\title{
Severe Maternal Morbidity in the Kisanga Health Zone in Lubumbashi, South of the Democratic Republic of Congo
}

\author{
Chola Mwansa Joseph ${ }^{*} \mid$ Zakaria Belrhiti $^{2} \mid$ Mpunga Mukendi Dieudonné ${ }^{3} \mid$ Kaya \\ Mulumbati Charles ${ }^{4}$ |Tamubango Kitoko Herman ${ }^{1}$ | Chuyi Kalombola Didier ${ }^{4}$ | Chola \\ Chembo Mildred $^{5} \mid$ Chenge Mukelenge Faustin $^{1,4} \mid$ Mwembo Tambwe Albert ${ }^{1,4}$
}

\begin{abstract}
${ }^{1}$ Department of GynecologyObstetrics, Faculty of Medicine, University of Lubumbashi, Lubumbashi, Democratic Republic of Congo
\end{abstract}

${ }^{2}$ Department of Public health, Morocco

${ }^{3}$ Department of Public health, School of Public Health, University of Kinshasa, Kinshasa, Democratic Republic of Congo

${ }^{4}$ School of Public Health, University of Lubumbashi, Lubumbashi, Democratic Republic of Congo

${ }^{5}$ Department of Pediatrics, Faculty of Medicine, University of Lubumbashi, Lubumbashi, Democratic Republic of Congo

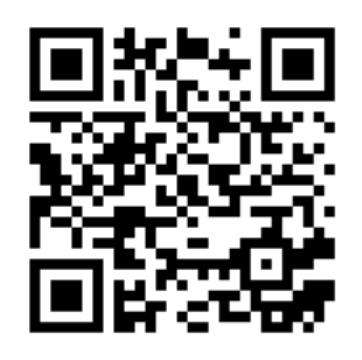

\begin{abstract}
While maternal death has traditionally been the primary indicator of maternal outcomes, the prevalence of severe pregnancy complications - or severe maternal morbidities - can provide a more complete picture of maternal and perinatal health issues when considered in conjunction with maternal deaths. The objectives of this work were to determine the prevalence of severe maternal morbidity, the socio-demographic characteristics of the patients, the conditions of admission and care as well as maternal and perinatal outcomes.

All women with severe maternal morbidity during 4 months of a descriptive cross-sectional study with prospective collect in the health zone of Kisanga in Lubumbashi were included in the study. These included cases of anemia, obstructed labor, hemorrhage, infections and high blood pressure. About one patient out of ten received in maternity hospitals in Lubumbashi presented with severe maternal morbidity. Genital haemorrhages (44.6\%), gestational hypertension (30.9\%) and obstructed labor (14.4\%) accounted for nearly $90 \%$ of the causes of severe maternal morbidity. Only three percent of the patients had access to a blood bank, $30 \%$ of the patients could have the opinion of a Obstetrician and only one in five patients remained in intensive care if necessary. The patients were young, married for most, coming from a semiurban environment with a low socio-economic level. No patient in this series had used the ambulance to get to the maternity ward. Maternal and perinatal mortality were 859 per 100,000 live births and 50 per 1,000 live births, respectively. The prevention and management of severe maternal morbidities requires an efficient and fully functional health system.
\end{abstract}

Keywords: Severe maternal morbidity, efficient health system, Lubumbashi

Copyright : (C) 2022 The Authors. Published by Medical Editor and Educational Research Publishers Ltd. This is an open access article under the CC BY-NC-ND license

(https://creativecommons.org/licenses/by-nc-nd/4.0/). 


\section{1 | INTRODUCTION}

A ccording to the results of the demographic and health survey conducted in 2013 in the Republic of Congo (EDS-RDC 2013-14), the maternal mortality rate was estimated at 846 per 100,000 live births and the neonatal mortality rate at 28 deaths for 1000 live births (1). Severe direct obstetric complications define severe maternal morbidity. The patients who survive the waning of these states are called Nearmiss, those who die represent maternal mortality. Maternal death passes, before it occurs, through an episode of severe maternal morbidity. Thereby, pregnant women who present with a serious obstetric complication (genital hemorrhage with signs of shock, eclampsia, severe maternal infection) and / or whose condition required major intervention to prevent death constitute severe maternal morbidity (2). It is estimated that for every death, another 50 women suffer from serious pregnancyrelated complications. While maternal death has traditionally been the primary indicator of maternal outcomes, the prevalence of severe pregnancy complications - or severe maternal morbidities - can provide a more complete picture of maternal and perinatal health issues when considered in conjunction with maternal deaths (3).This analysis makes it possible to trace the dysfunctions in the care of patients. These dysfunctions are found at all stages of patient care: emergency care, inpatient care follow-up, patient discharge and information from the medical file. The majority of dysfunctions occur at critical times when patients are very vulnerable and most in need of sufficient and quality care (4). In our environment, where maternal mortality remains high, it is important to assess the characteristics of women with severe maternal morbidity and the conditions of their care. The description of severe maternal morbidity may explain the risk factors for maternal mortality. Thus, we will determine the prevalence of serious maternal morbidity, the socio-demographic characteristics of the patients, the conditions of admission and treatment as well as the maternal and perinatal outcomes.

\section{2 | METHODOLOGY}

This study was carried out in the city of Lubumbashi in the maternities of the Kisanga health zone for 4 months, from January to April 2019. It was carried out in 5 large maternities, namely that of the General Reference Hospital of Kisanga / La Foi, Mama wa Huruma maternity, Saint Bernadette maternity, Utukufu maternity and Jason Sendwe Provincial General Hospital.

Data were taken prospectively. All women with severe morbidity were included in the study. These included cases of anemia, obstructed labor, hemorrhage, infections and high blood pressure.

A total of 139 cases of severe maternal morbidity were collected, distributed as shown in the following table: 30 cases at the Kisanga / La Foi General Referral Hospital, 32 at the Jason Sendwe Provincial General Referral Hospital, 47 at the Mama wa Huruma maternity, 24 at Sainte Bernadette maternity and 6 at Utukufu maternity

Table 1 : Distribution of cases of severe maternal morbidity by structure

\begin{tabular}{lll}
\hline Structure & Effective $(\mathrm{n}=139)$ & Percentage $(\%)$ \\
\hline HGR Faith & 30 & 21.60 \\
HGR Sendwe & 32 & 23.00 \\
Mama Wahuruma & 47 & 33.80 \\
Utukufu Maternity & 6 & 4.30 \\
Saint Bernadette & 24 & 17.30 \\
\hline
\end{tabular}

During the same period, there were 1,280 live births

Supplementary information The online version of this article (https://doi.org/10.52845/JMRHS/20225-1-2) contains supplementary material, which is available to authorized users.

Corresponding Author: Chola Mwansa Joseph Department of Gynecology-Obstetrics, Faculty of Medicine, University of Lubumbashi, Lubumbashi, Democratic Republic of Congo 

OF THE DEMOCRATIC REPUBLIC OF CONGO

This is how severe maternal morbidity was defined

Definition of severe maternal morbidity (5)

\section{ANEMIA (OTHER CAUSE THAN HEMORRHAGE)}

Hemoglobinemia $\leq 5 \mathrm{~g} / \mathrm{dL}$ or Very pale mucous membranes and shortness of breath or Very pale mucous membranes and edema of the lower limbs or generalized or or necessity of blood transfusion without any notion of bleeding

\section{OBSTRUCTED LABOR}

Uterine rupture or Pre-rupture syndrome

\section{PROFUSE GENITAL HEMORRHAGE}

Defined as external or internal blood loss (observed or reported) and at least two of the following signs of shock: pale con-junctiva, systolic blood pressure (SBP) less than or equal to $80 \mathrm{~mm} \mathrm{Hg}$, rapid or impregnable pulse, cold extremities, intense thirst, disturbance of consciousness; Necessity of Hysterectomy or transfusion or cesarean sec-tion or laparotomy or delivery hemorrhage, cervical and or vaginal lesions or extra-uterin pregnancy.

\section{SEVERE POSTABORTION OR POSTPARTUM INFECTION}

Hyperthermia $\left(\mathrm{T}^{\circ}>37^{\circ} 5\right)$ or hypothermia $\left(\mathrm{T}^{\circ}\right.$ $<36^{\circ} 5$ ) and infectious focus and at least one of the following signs: Systolic blood pressure $<80 \mathrm{~mm} \mathrm{Hg}$, disturbances of consciousness, jaundice and oliguria $100 \mathrm{ml}$ in 4 hours.

\section{HIGH BLOOD PRESSURE}

Blood pressure $\geq 160 / 110 \mathrm{mmHg}$ or $140 / 90 \mathrm{~mm} \mathrm{Hg}$ (or PAS variation $\geq 30 \mathrm{~mm} \mathrm{Hg}$ or $\mathrm{PAD}>15 \mathrm{~mm} \mathrm{Hg}$ ) and at least one of the following signs: Coma, jaundice, oliguria (100 $\mathrm{ml} / 4 \mathrm{~h})$, thrombocy-topenia $<100$. 000 platelets, massive proteinuria; or eclampsia or convulsion or at least two of the following signs: blurred vision, epigastric bar, headache in helmet, ringing in the ears, massive proteinuria and generalized edema.

For each case detected, the following information was collected: the technical platform of the structure, the period of gravido-puerperium (gestation, parturition, postpartum), the socioeconomic and demographic characteristics of the patient, The gynecological and obstetrical history,the conditions of admis-sion, and the occurrence of the state of seriousness, the dates and times of emergency procedures upon arrival of the patient, the dates and times of decision-making and execution of medical and surgical care, dates and times for obtaining laboratory results, fre-quency of clinical monitoring items (blood pressure, temperature and pulse) and pregnancy outcome and method of patient discharge.

The socio-economic level was calculated from the following variables: a) number of years spent in school for the beautiful and joint breakaway rated at 30 points; employment of the escapade and his spouse rated at 4 points and the occupancy status of the current accommodation at 5 points $(5=$ Owner; $4=$ Tenant; $3=$ Housed by the employer; $2=$ underhoused ; $1=$ site guard). The total score retained is 39 points. Assessment of the level is classified as follows: rating less than $15=$ low level, rating varying between 13-26 = medium level and rating greater than 26: high level.

\section{3 | RESULTS}

\section{Prevalence of cases of severe maternal morbidity}

About one patient out of ten seen in maternity hospitals in Lubumbashi presented with severe maternal mor-bidity.

\section{Etiologic diagnosis of severe maternal morbidity}

Table II shows that genital haemorrhages (44.6\%), pregnancy-induced hypertension $(30.9 \%)$ and obstructed labor (14.4\%) represent nearly $90 \%$ of the causes of serious maternal morbidity. Infections were very poorly represented $(3.6 \%)$. 
MEERP LTD

Table II: Distribution of cases of severe maternal morbidity according toetiological diagnosis

\begin{tabular}{lcc}
\hline Clinical diagnosis & Effective (N = 139) & Percentage (\%) \\
\hline Genital haemorrhage & 62 & 44.6 \\
Pregnancy hypertension & 43 & 30.9 \\
Obstructed labor & 20 & 14.4 \\
Anemia & 9 & 6.5 \\
Infection & 5 & 3.6 \\
\hline
\end{tabular}

\section{Period of onset of severe maternal morbidity}

Almost two out of five complications were observed during parturition and then in the postpartum period, with nearly one in three complications.

Table III: Distribution of cases of severe maternal morbidity according to Pregnancy-puerperium period

\begin{tabular}{lll}
\hline Pregnancy-puerperium period & Effective $(\mathbf{n}=139)$ & Percentage \\
\hline Gestation & 23 & 16.50 \\
parturition & 53 & 38.10 \\
postpartum & 41 & 29.50 \\
from gestation to postpartum & 17 & 12.20 \\
two periods combined & 5 & 3.60 \\
\hline
\end{tabular}

\section{Resources available for admission}

$\mathrm{V}$ indicates that only $30 \%$ of patients could benefit from an opinion from a GynecologistObstetrician. Only three percent of patients had access to a blood bank. One out of five patients had access to a resuscitation room. The resources available were drugs (antibiotics, antihypertensives, anticonvulsants and uterotonics)

TABLE IV: Resources available for admission

\begin{tabular}{lrr}
\hline Availability of inputs and human resources & Effective $(\mathbf{n}=\mathbf{1 3 9})$ & Percentage \\
\hline Presence of an obstetrician-gynecologist & 42 & 30.20 \\
Presence of a blood bank & 4 & 2.90 \\
Presence of an oxygen concentrator & 29 & 20.90 \\
Presence of a resuscitation room & 29 & 20.90 \\
Availability of anticonvulsants & 127 & 91.40 \\
Availability of uterotonics & 128 & 92.10 \\
Availability of antiliypertensive drulgs & 126 & 90.60 \\
Availability of antibiotics & 128 & 92.10 \\
Availability of solutes & 122 & 87.80 \\
\hline
\end{tabular}

\section{Sociodemographic characteristics of patients}

The patients were in the age group of 18 to 35 years, mostly married, coming from a semi-urban environ-ment with a low socio-economic level unrelated to parity.

\section{TABLE V: Sociodemographic characteristics of the patients}

Settinos - Pefective $(n=139)$ Percentage

age range

\begin{tabular}{lrr}
$<18$ & 7 & 5.04 \\
$18-35$ & 104 & 74.82 \\
$>35$ & 26 & 18.71 \\
Not precise & 2 & 1.44 \\
\hline Marital status & 3 & \\
Single & 120 & 2.2 \\
Married & 2 & 86.3 \\
Divorcee & 1 & 1.4 \\
Widow & 11 & 0.7 \\
free Union & 2 & 7.9 \\
not precise & & 1.4 \\
\hline
\end{tabular}

\begin{tabular}{lrr}
\hline Origin & & \\
Urban & 12 & 8.63 \\
Semi-urban & 117 & 84.17 \\
Rural & 3 & 2.15 \\
not precise & 7 & 5.04 \\
\hline
\end{tabular}

Socio-economic level

$\begin{array}{lll}\text { Low level } & 101 & 72.66\end{array}$

$\begin{array}{lll}\text { Average level } & 38 & 27.34\end{array}$

High level

0

Parity

Nulliparous

24

17.27

Pauciparous

15.83

Multiparous

Large multipare

not precise 


\section{Conditions of arrival at the hospital}

No patient in this series had used the ambulance to get to the maternity ward. On the other hand, nearly $45 \%$ of the patients came using other means than the car: it was either by motorbike, or by bicycle, or on foot.

TABLE VI: Conditions of arrival at the maternity ward

\begin{tabular}{lll}
\hline Means of transport & Effective $(\mathbf{n}=\mathbf{1 3 9})$ & Percentage \\
\hline Ambulance & 0 & 0 \\
Car & 77 & 55.4 \\
Motorbike & 40 & 28.78 \\
Bike & 1 & 0.72 \\
Feet & 13 & 9.35 \\
Not precise & 8 & 5.76 \\
\hline
\end{tabular}

\section{Intervention deadlines}

Table VII shows that it takes more than 2 hours for a cesarean section, a laparotomy or even a curettage.

TABLE VII: Response time

\begin{tabular}{lcc}
\hline Emergency actions & $\begin{array}{c}\text { Effective }(\mathbf{n} \\
\mathbf{1} 139)\end{array}$ & $\begin{array}{c}\text { Median (Q1-03) } \\
(\mathrm{min})\end{array}$ \\
\hline Consultation timing & 116 & $12(5-30)$ \\
Timing of the venous route & 89 & $12(8-35)$ \\
Laboratory sampling timing & 73 & $12(11-112)$ \\
Antilhypentensive administration timing & 26 & $12(10-73)$ \\
Timing to perform a currettage & 10 & $121(81-211)$ \\
Timing to admininister an antibiotic & 18 & $12(13-212)$ \\
Timing to perform a uterine revision & 4 & $115(30-200)$ \\
Timing to perform a Caesarean / Laparotomy & 20 & $137(51-351)$ \\
Timing to obtain Blood Groupage results & 54 & $59(20-360)$ \\
\hline
\end{tabular}

\section{Maternal and perinatal outcomes}

Of these 139 patients, $11(8 \%)$ had died. The others (128 patients) constitute the groupe of nearmiss. In view of the number of live births that there were in these maternities, maternal mortality was 859 per 100,000 live births. The perinatal lethality was $46 \%$; perinatal mortality was 50 per 1000 live births.

Table VIII: Maternal and perinatal outcomes

\begin{tabular}{lll}
\hline Maternal outcome & Effective & Percentage \\
\hline Living & 128 & 92.09 \\
Died & 11 & 7.91 \\
\hline Newborn issue & & \\
\hline Living & 75 & 54.0 \\
dead & 64 & 46.0 \\
Total & 139 & 100.00 \\
\hline
\end{tabular}

\section{4 | DISCUSSION}

Serious maternal morbidity was $10 \%$ in this series. It was described in the MOMA (Maternal Mortality in Africa) study since 2010 (5) at $6.7 \%$ in West Africa, which is slightly lower than the values found in Lubumbashi. It was still a little lower $(5.9 \%)$ in Ouagadougou in 2001 (6) . It was already less than one percent in the United States in 2014 (7). Indeed, severe maternal morbidity is an indicator of maternal health. It is also an indicator of a country's development. The data presented above shows that it is quite high in developing countries than in industrialized countries.

The etiologies were represented by hemorrhages, hypertension and dystocia. The 3 causes have already made $90 \%$ of the causes. Even in the West, where obstetrics have evolved markedly, postpartum hem-orrhage remains a major cause of severe maternal morbidity (8).A global vision of serious maternal morbidity: going beyond maternal mortality (9) shows that in Sub-Saharan Africa, serious maternal morbidity can reach $19.8 \%$ and the main etiologies alternate in their places but they remain made up of hemorrhages, hypertensive disorders, infections, 
obstructed labor and complications of abortions. In Namibia (10), Over a 6-month period, 37,106 live births were registered, obstetric hemorrhages and hypertensive disorders were the most common causes of severe maternal morbidity (92/298 each; 30.9\%). Of the 49 maternal morbidities due to young pregnancies, ectopic pregnancy was the most common cause $(36 / 298 ; 12.1 \%)$.

We can therefore only meet the challenge of serious maternal morbidity if our maternities become able to fight against these complications in terms of infrastructure, equipment, funding and personnel.

Regarding the availability of resources, only $30 \%$ of patients received an opinion from a gynecologistobstetrician, who, in the majority of cases, was not available when the patient arrived. Access to a blood bank was very limited (3\%). One in five patients could be admitted to intensive care. These conditions greatly increase maternal mortality. In a study carried out in Zanzibar (11) in African areas with low resources, showed that the insufficiency of the technical platform multiplies by 6 the ratio of maternal mortality. Contributing factors for severe maternal morbidity were lack of resources, poor quality of primary health care, and delays in care. All serious maternal morbidities should be considered as opportunities for improve the quality of maternity care. Health institutions should address delays in delivering interventions, barriers to referral, and gaps in staff. Fully functional intensive care units should be created in all institutions. Notification policies for all averted cases of severe maternal morbidity should be in place in all health care units, with a "no shame, no blame" approach (12).

The same is true for non-medical conditions of reaching maternity hospitals and the time required for major interventions. This was also observed elsewhere where there was severe maternal morbidity. For the majority of women who had risk factors for severe maternal morbidity, there were significant delays in ambulances and a lack of health facilities. All the women needed life-saving interventions, but could not access appropriate care on time. The prevention and management of severe maternal morbidities requires a fully functioning, effective health system (13).
The time taken to take charge was long, reaching more than 2 hours. In Ivory Coast, The management of serious maternal morbidities in the emergency room was concerned by $39.6 \%$ of the dysfunctions. The delays in taking over were noted during the taking over. The time to treatment, all complications combined, varied from 1 hour 20 minutes to 120 hours (median 60 hours) at the Cocody site and from 20 minutes to 3 hours 28 minutes (median 1 hour 45 minutes) at the FS d'Abobo-sud. The median delays in the 2 structures were respectively $2 \mathrm{~h} 19 \mathrm{~min}, 1 \mathrm{~h} 30 \mathrm{~min}$ and $25 \mathrm{~min}$ for hypertensive complications, hemorrhages, and anemia. The other dysfunctions observed in emergency management were linked to the diagnosis, treatment and followup of the patient (14).

In this series, the patients were young, mostly married, coming from a semi-urban area and having a low socioeconomic level. The socio-economic level could partly explain the severe maternal morbidity.

It was observed that $11(8 \%)$ of the 139 patients had died and 64 (46\%) newborns as well, resulting in a maternal mortality of 859 per 100,000 live births and a neonatal mortality of 50 per 1,000 births. The fatality prevalence of severe maternal morbidities ranges from $3.1 \%$ to $37.4 \%$ (15). In Tanzania, the incidence rate of severe maternal morbidities was 23.6 per 1000 live births, with an overall case fatality rate of $12.9 \%$. These different results show that severe maternal morbidity is followed by strong maternal morbidity. Thus, proper management at all levels of severe maternal morbidity conditions would help reduce maternal mortality.

\section{5 | CONCLUSION}

Severe maternal morbidity is a real public health problem in Lubumbashi. It affects one in ten women. The victim populations are young, married, coming from semi-urban areas with a low socio-economic level. The care process is inadequate marked by insufficient resources at the level of patients, health institutions and the health system. In Lubumbashi, serious maternal morbidity is an important fact that is rampant in large hospital institutions. It appears to be the consequence of inadequate prenatal care, an imperfect referral system and delayed care severe 
maternal morbidity has a high lethality. The prevention and management of severe maternal morbidities requires an efficient and fully functional health system.

\section{SPONSORSHIP}

This study was sponsored by RIPSEC (Renforcement Institutionnel des Politiques de Santé basée sur l'évidence en RDC)

\section{COMPETING INTERESTS}

The authors declare no competing interest

\section{REFERENCES}

1. Planning MO. 2013-2014 Demographic and Health Survey II, final report. In: Ministry of Public Health (DRC); 2014. .

2. Sosthène MT, Jean-François M, Isabelle AT, Thierno N, Litovchenko D, Gabriel O, et al.; 2007.

3. Gibson C, Rohan AM, Gillespie KH. Severe Maternal Morbidity During Delivery Hospitalizations. WMJ. 2017;116(5):215-220.

4. Touré B, Koffi NM, Gohou-Kouassi V, Dagnan NS, Diarra-Nama AJ. Identification of dysfunctions in the management of severe maternal morbidity in Abidjan. In: Public health2005. vol. 1; p. 135-144.

5. Prual A, Bouvier-Colle MH, Bernis L, G. Severe maternal morbidity from direct obstetric causes in West Africa: incidence and lethality. Bulletin of the World Health Organization. 2000;78(5):593-602.

6. Ouedraogo C, Testa J, Sondo B, Kone B. Analysis of risk factors for severe maternal morbidity in OUAGADOUGOU, Burkina Faso Application to the prenatal consultation form. Black African Medicine. 2001;(10):48-48.

7. Gibson C, Rohan AM, Gillespie KH. Severe Maternal Morbidity During Delivery Hospitalizations. WMJ. 2017;116(5):215-220.
8. Ray JG, Park AL, Dzakpasu S. Prevalence of Severe Maternal Morbidity and Factors Associated With Maternal Mortality in Ontario, Canada. JAMA Netw Open. 2018;1(7):184571-184571.

9. Geller SE, Koch AR, Garland CE, Macdonald EJ, Storey F, Lawton B. A global view of severe maternal morbidity: moving beyond maternal mortality. Reprod Health. 2018;15(1):98-98.

10. Heemelaar S, Josef M, Diener Z. Maternal nearmiss surveillance. Namibia Bull World Health Organ. 2020;98(8):548-557.

11. Herklots T, Acht LV, Meguid T, Franx A, Ja$\operatorname{cod}$ B. Severe maternal morbidity in Zanzibar's referral hospital: Measuring the impact of inhospital care. PLoS One. 2017;12(8).

12. Alemu FM, Fuchs MC, Vitale M, T, Salih AM, M. Severe maternal morbidity (near-miss) and its correlates in the world's newest nation: South Sudan. Int J Womens Health. 2019;11:177-190.

13. Maswime TS, Buchmann E. Near-miss maternal morbidity from severe haemorrhage at caesarean section: A process and structure audit of system deficiencies in South Africa. S Afr Med J. 2017;107(11):1005-1009.

14. Touré B, Koffi NM, Gohou-Kouassi V, DiarraNama. Identification of dysfunctions in the management of severe maternal morbidity in Abidjan. Public Health. 2005;17(1):135-144.

15. Kaye DK, Kakaire O, Osinde MO. Systematic review of the magnitude and case fatality ratio for severe maternal morbidity in sub-Saharan Africa between 1995 and 2010. BMC Pregnancy Childbirth. 2011;11.

How to cite this article: C.M.J., Z.B., M.M.D., K.M.C.,T.K.H., C.K.D., C.C.M.,C.M.F.,M.T.A. Severe Maternal Morbidity in the Kisanga Health Zone in Lubumbashi, South of the Democratic Republic of Congo. Journal of Medical Research and Health Sciences. 2022;1647 -1652. https://doi.org/10.52 845/ JMRHS/ 2022 $-5-1-2$ 